162 Entuickelungsgeschichte des Farbstoffs in Pfanzenzellen.

sind. Beim Erhitzen verpuffen sämmtliche Salze wie Schiesspulver. Eine geringe Menge des Kalisalzes in Wasser geworfen löst sich mit intensiver dunkelviolettrother Farbe auf. (Annal. der Chem. und Pharm. CXXXIV. $229-236^{\circ}$ )

$G$.

\title{
Chloranil.
}

Behandelt man eine alkoholische Lösung von Capaloë mit Chlor, so trennt sich die Flüssigkeit in zwei Schichten, wovon die obere Producte der Einwirkung von Chlor auf Alkohol enthält, während die untere aus einem orangegelben halbflïssigen Harze besteht, welches sich in kaltem Weingeist mit rothbrauner Farbe löst, unter Abscheidung von gelblich-weissen Krystallblättchen. Diese Krystalle sind nach der Untersuchung von C. Finckh Chloranil $=\mathrm{C}^{12} \mathrm{Cl}^{4} \mathrm{O}^{4}$ (Annal. der Chem. und Pharm. CXXXIV. $241-242$.)

$G$.

\section{Untersuchungen über die Entwickelungsgeschichte des Farbstoffs in Pflanzenzellen}

hat $\Lambda$ dolf $W$ eis s (Prof. der Botanik an der Universität Lemberg) veröffentlicht. Er stellte dieselben mit den Beeren von Lycizm barbarum L., Solanum Dulcamara L., Solanum capicastrum Lk, Solanum laciniatum Ait., Solanum pseudocapsicum L., den Zellen des gelben Ueberzugs, der die Samen von Evonymus europaeus $L$. bekleidet, den Beeren von Capsicum baccatum, Asparagus verticillatus $L$. an, welche sämmtlich cinen nicht gelöst auftretenden gelbrothen Farbstoff enthalten und fasst die Resultate seiner mitgetheilten und durch schöne colorirte Abbildungen erläuterten Beobachtungen in folgende allgemeinere Süitze zusammen:

1. Die Bildung des Farbstoffes erfolgt in einer und derselben Zelle fast immer auf zwei oder mehre von einander verschiedene Weisen.

2. Sie geschieht nicht in der Weise, dass etwa die Chlorophyllkörner zuerst verschwinden und durch Neubildung sich auf einer neuen Unterlage neuer Farbstoff erzeugt, sondern indem die Unterlage des früheren Chlorophyllkorns (wohl meist $A$ mylum) bleibt und nur das grüne Pigment, welches sich unter Einwirkung des Lichtes darauf abgelagert hatte, succesive durch alle Abstufungen von Gelb hindurch in den schliesslich rothgelben Farbstoff verwandelt. 
3. Die Ursache dieser Farbenwandlung muss in einer durch die Vorgänge des Reifens der Beere veränderten Diffusionsthätigkeit der Zellen gesucht werden, obgleich sich derzeit über die zu Grunde liegenden chemischen Verhältnisse nichts angeben lässt.

4. Neben dieser bei weitem häufigsten Bildungsart kommt gewöhnlich eine zweite von ihr gänzlich verschiedene vor, durch welche im Innern von Bläschen der Farbstoff direct aus dem Protoplasma oder richtiger aus der stickstoffhaltigen Materie im Innern derselben entsteht.

5. Die fertigen Farbstoffgebilde erhalten später an ihren Enden meist farblose Schleimfäden, welche zwei oder mehre derselben verbinden und möglicherweise das Product einer Umwandlung sein können, welche die Unterlage (Amylum) des Farbstoffs bei und nach der Reife erfährt.

6. Schliesslich zerfallen die Farbstoffgebilde, indem ihr Pigment allmälig immer blässer und blässer wird, in ihre einzelne Theile (Unterlage und Pigment).

Weiss bedient sich in seiner Abhandlung des Ausdruckes Bläschen zur Bezeichnung eigenthümlicher Gebilde im Innern von Pflanzenzellen und er spricht sich über dieselben dahin aus:

Es ist sicher, dass im Innern von Zellen eine Art von Elementarorganen, $\mathrm{Bl}$ äschen, vorkommen, die aus einer Membran und einem von ihr scbarf getrennten fluesigen Inhalte bestehen, in oder aus welchem sich im Verlaufe ihres Lebens Amylum, Chlorophyll und Farbstoffe bilden können, die demnach wie die Zellen selbst eine fortschreitende Entwickelung zeigen. Ihr Unterschied von dem, was wir Zelle nennen, dürfte kaum darin bestehen, dass sie ohne Einwirkung eines Cytoblasten sich individualisiren, jedenfalls aber, dass wir an ihnen vor der Hand keine Cellulosehülle nachweisen können, ja dass sie dieselbe höchst wabrscheinlich durchaus nicht besitzen. Generisch sind sie von unseren Zellen sicher nicht verschieden. Was den Cytoblasten betrifft, so wird ihm ebenfalls sicher die Zellennatur zugesprochen werden müssen. (Sitzungsber. der k.k. Akad. der Wissensch. Math.-naturu. Cl. 50. Bd. I. Heft. I. Abth. S. $6^{\circ}-35$.)

H. Ludwig. 